\title{
The Creation of Multimedia Resources to support the Gaelic Athletic Association (GAA) Coach Education Programme (CEP)
}

DOI 10.1515/ijtr-2016-0011

received September 2016; accepted November 2016

\begin{abstract}
The Gaelic Athletic Association (GAA) is an Irish amateur sporting and cultural organisation. It represents in excess of 20,000 teams nationwide and is committed to supporting the development of players and coaches through its Coach Education Programme (CEP). A strategic goal of the CEP is to supplement the traditional field based coach education model with a blended learning approach using online multimedia resources. Two eLearning professionals employed by the GAA are seeking to develop online resources to enhance the knowledge and skills of coaches nationwide. Whilst both professionals possess the expertise and relevant technical skills to create high quality resources, their participation in a Masters in Education and Training Management (eLearning) programme in the Institute of Education, Dublin City University (DCU) is ensuring that the multimedia resources will be based on solid pedagogical insights in order to facilitate the organisation's move to online learning.
\end{abstract}

Keywords: eLearning; Multimedia; Blended learning; Practitioner research; ePortfolios; Pedagogy

\footnotetext{
*Corresponding author: Yvonne Crotty, School of STEM Education, Innovation and Global Studies, Institute of Education, St. Patrick's Campus, Drumcondra, Dublin 9, Ireland, Email: Yvonne.Crotty@dcu. ie

Jimmy D’Arcy, David Sweeney, GAA, Croke Park, Dublin 3, Ireland
}

\section{Introduction}

This article highlights the efforts of two eLearning professionals in the Gaelic Athletic Association (GAA) in Ireland who wish to bring about change in their organisation through the creation of pedagogically sound multimedia resources that will help to transform learning in the GAA. The multimedia technologies chosen by the two GAA professionals will serve to enhance and impact on the organisation's approach to teaching and learning, which will be explored in more detail in this article.

The motivation for change came about through their participation in the Masters in Education and Training Management (e-Learning) programme (hereafter called Masters) in the Institute of Education at Dublin City University (DCU), as both professionals were encouraged to reflect on the culture of their organisation, their values, their vision, and the most effective multimedia technology that would improve their practice. Of significant value to this study is the emphasis on the professionals' collaboration with the DCU programme, as it is enabling them to develop more educationally sound multimedia resources for the GAA through their research studies.

Their passion for the promotion of Gaelic games and, in particular, the development of the role of the coach in Gaelic games have informed the focus of their Masters research and the content of their multimedia resources. The GAA run a Coach Education Programme (CEP), which focuses on continuing education, so that coaches can improve by means of a series of specifically designed courses, workshops and conferences. This will be elaborated on in the following section, as both professionals seek to implement multimedia technologies to enhance the knowledge and performance of coaches through this programme.

Firstly we will outline the background to the GAA and its CEP. Next the professionals' context is explained, while also identifying key aspects of the Masters that is providing the professionals with a solid pedagogical grounding for their research work. A discussion then follows, which 
documents the vision, research approach, and theoretical frameworks that both have established throughout the programme, in their determination to create a better future for GAA coaches throughout Ireland.

\section{Background}

\subsection{GAA}

Gaelic games are recognised as part of the culture of Ireland and have been governed by the GAA since its foundation in 1884. Gaelic games include hurling, Gaelic football, handball, and rounders. As the basic unit of the Association, there are over 2,300 GAA clubs across the island of Ireland - 32 counties - representing every parish, competing against each other and promoting all or some of the GAA games. It is an amateur sporting organization, which is community based and volunteer led. Along with club teams, teams representing geographical divisions and counties as well as primary schools, post-primary schools and third level institutes combine to total in excess of 20,000 registered teams annually. That is a lot of teams to be coached and many players for whom the quality of coaching is not only relevant to their performance and development but more fundamentally to their continued participation (Balish et al., 2014).

\subsection{The GAA Coach Education Programme (CEP)}

The GAA CEP focuses on continuous education so that grassroots sports coaches in particular are provided with recognition as well as qualifications that optimise their effectiveness and their unique contributions. The coach's learning journey in the GAA is referred to as a programme of Applied Lifelong Learning (ALL) and it aims to make provision for coaches to continually develop their skills and to progress at a rate suited to their own development. This programme framework is founded on value-laden principles and aims to track volunteer service, record and recognise social capital benefits from an individual, team or community perspective.

Currently the CEP courses are offered at the following stages: Foundation, Award 1 and Award 2. At foundation level the county coordinators have the option of running the traditional face-to-face course over two days, or a blended approach that encompasses 4 hours of interactive online theory based work and a separate 4 hour practical session. There is also the option to run online workshops in concussion awareness, anti-doping awareness and camp supervision training. Award 1 and Award 2 courses remain fully classroom/field based but the plan for 2016/17 is to create blended versions for these awards also. However, while in general the blended foundation course has been met with a positive response, there has been limited uptake in some counties.

A strategic goal of the CEP is to supplement the traditional field based coach education model with multimedia content using a blended learning approach. This blended model should support the development of communities of practice, both physical and virtual, and allow for the growth of mentorship programmes between coaches of varying experiences and qualifications. The aim is that the implementation of an ePortfolio for all participants in the programme will contribute significantly towards the achievement of this goal and the development of the ALL concept. An integrated ePortfolio is seen as an important part of the overall eLearning suite of resources for GAA members.

\section{Context}

\subsection{Professionals' context}

Both professionals are participants in the Masters programme. Professional 1 is an eLearning and multimedia resource developer whose key responsibility is coach education and working with coordinators in all 32 counties and 5 regional coordinators, in delivering the online and blended options of the GAA courses. As part of his Masters research he is aiming to create an online multimedia resource to inform coaches of the benefits of maintaining a Mahara ePortfolio as an educational tool, in support of their development within the GAA Coach Education Programme. The genesis of this idea stemmed from a concern about coaches' lack of engagement with the GAA's ePortfolio, Mahara:

our experience to date with Mahara is that unless it is compulsory and unless the coach can see an immediate benefit to creating a profile, engagement is quite low. (Professional 1)

Professional 2 is a Technical Development and Support Manager whose main responsibility is to implement eLearning initiatives to support the development of GAA coaches. As part of his Masters research he is seeking to 
produce a video that will communicate a new model of coaching to GAA coaches. The video aims to help coaches improve their understanding of their practice and therefore enhance their overall performance. The production of the video will not only encourage greater understanding among those he will collaborate with, but it will also serve to develop his own personal and professional relationship with them. The origin of this idea stemmed from a concern about the current methods of CEP training which is considered too traditional and didactic in nature. This issue was validated by Professor Bryan Mc Cullick - University of Georgia, Atlanta - who, having reviewed the GAA CEP in 2012, found that:

The current modes of program delivery are more "formal" in nature and do not include alternatives that are less formal (e.g., Online Modules \& Mentoring Programs) and/or informal (Communities of Practice) in conjunction with face-to- face delivery. Recent research in the area of Coach Education indicates that coaches can, and may prefer to, learn via multiple ways and to understand, acknowledge, and integrate those ways of learning is to increase the prospects of coaches developing their knowledge and skills (Mc Cullick, 2012).

Another reason for both professionals' agency stems from their concern about their organisation's lack of an e-Learning vision and a perceived reluctance during the face-toface training to share information between members of different clubs and counties, both inside and outside the CEP structure:

This reluctance may be associated with a fear of losing a competitive advantage on the playing field, and is reinforced at local programme events by the participants' familiarity with one another through local competitions. (Professional 2)

Reluctance among individuals to share information inadvertently becomes part of a cultural problem (Schein, 2014). Furthermore, while the GAA's vision provides for the development of a learning culture, it does not currently provide for eLearning specifically.

Both professionals concur that there is a need to be proactive and become champions (leaders) in their organisation to lead the transition from the traditional face-toface training to a more blended approach:

My own view is that the most important factor in the successful engagement with any initiative is the individual charged with driving the project. This important factor is referred to as the Champion (Rosenberg 2001), i.e. the leader who drives the project. There can always be a resistance to change and a fear of the unknown but I believe that with the right person at the helm who is enthusiastic about the change, then the other constraints become secondary. (Professional 1)
As suggested by Schein (2014), by doing little or nothing to model the behavior I want to see, I admit that I may have been "reinforcing the cultural rigidity". By immersing myself in the use and active promotion of the eLearning system, I will be able to adapt my leadership style and challenge my colleagues and fellow stakeholders as to what they are doing to promote the eLearning system, and develop a learning culture within the GAA. (Professional 2)

There lies the challenge and opportunity for both professionals, as they can use their pedagogical knowledge and skills, which have been enhanced on the Masters programme, to lead, change and transform the GAA CEP eLearning culture. These challenges, opportunities and transformations will be discussed.

\section{Discussion}

\subsection{Vision}

\subsubsection{Professional 1}

Professional 1's vision is to create an interactive online multimedia resource, using Articulate Storyline 2 - an authoring tool for creating online courses - to advise GAA coaches of the benefits of Mahara ePortfolio software and how it can help them develop in their roles. As part of the Multimedia and Educational Innovation module in year one of the Masters he created a video (goo.gl/VtZQJc) for coaches which highlighted the benefits of keeping an ePortfolio, such as its use as a reflective tool and in supporting virtual communities of practice. His research resource will reinforce the content from the video, but also more importantly, educate the coach on reflection itself and not just the benefits of doing it. The fundamental end use of his research is to form part of the online support for the new revision of the GAA Award 2 programme due in 2017. This is the most advanced coaching award currently offered by the GAA and this revision will be delivered in a blended format. Another aim of the resource is to guide the user through Mahara ePortfolio in such a way that it simulates the use of the software. The intention is for the user to learn from the experience of doing and not just by seeing as would be the case with the instructional video alone.

Overall, this multimedia resource represents a change from how the Award 2 is currently delivered where it is fully face-to-face and the participating coaches keep a physical log book during their time on the course. In order to maximise the coaches' use and interaction with the 
software, he will draw upon literature in the field of interactivity, experiential learning and social constructivism.

\subsubsection{Professional 2}

Professional 2's vision is to create a video resource to communicate the new Coach 10 Model of effective coaching which is an initiative devised by Pat Daly (2014, p. 28), the GAA Director of Games Development and Research. The model is designed to identify the components of effective coaching, their connections and their significance, and ultimately support coaches in reflecting on and understanding their coaching practice (Horgan and Daly, 2015). The multimedia resource that will be developed to support the model will be freely accessible to GAA coaches and the public on the GAA learning platform and YouTube channel. It will also form a key resource in the renewed CEP. It is his intention that the video not only informs the viewer of the components of the model and how they relate to each other, but does so by communicating some of the applied knowledge of a "real" coach or coaches as they share their story and experience in the production. This enables the viewer to connect to those experiences that are common and familiar to them, and provides them with a context for reflection on their current understanding of coaching, their own practice and how it aligns to this new model.

Having been involved in the GAA since childhood - as player, coach, and now as an employee - he is in a unique position to combine his experience and skills to communicate the essential elements of the new coaching model through a video production. Thanks to his current position he has an opportunity to have an impact on the development of coaching practice in the GAA. Furthermore, it is his aim to reinforce the aspect of coaching that he feels in many ways matters the most: the development of a supportive relationship between the coach and the player. He feels that it is through this relationship that one has an opportunity to learn. He confirmed this feeling in his very first journal entry on the Masters programme:

When completing the task to identify my educational values I thought about a number of things...I (also) chose 'Collaboration'...This choice was closely linked to my belief in education as being the outcome of better connections. (Professional 2, personal communication, 30 September 2015)

He will draw upon literature in the field of coaching models, good practice in video production and the development of a unique sense of understanding and meaning through storytelling and engaging with another's story.
This final theme of storytelling is significant to his research as it provides an opportunity to build on his desire to reinforce, through personal narrative, the supportive relational dynamic between coach and player.

\subsection{Research Approach}

Both professionals are using an educational entrepreneurial approach to action research (Crotty, 2014) in their enquiries as they create innovative multimedia resources to transform learning in their work context. Exploration, Understanding, Creating, Transforming are the four key stages in the approach while the action research cycles of plan, act, observe and reflect form an essential part of the process. The three key characteristics that define the Educational Entrepreneurial Approach include:

1. Engaging the imagination in the possibilities opened up by new forms of multimodal communication and building the capacity of practitioners to design and create multimedia resources for use in their own work context. The multimedia resources are designed to transform workplace practices.

2. The values of passion, creativity and excellence underpin the Educational Entrepreneurial Approach. The practitioner researcher also articulates their own educational values which act as guiding principles throughout their enquiry.

3. The knowledge created is a cooperative process involving the practitioner researcher and the university in the service of the wider social context. There is a performance element as part of the researcher's journey as they regularly present their ongoing research in order to get feedback that will help to strenghten the overall enquiry (Crotty and Kilboy, 2015).

\subsection{Pedagogy}

As evident in this section both professionals' engage with current literature in relation to the creation of the multimedia resource and this has ensured that their resource is not just based on technical skills and knowledge, but is as importantly grounded in sound pedagogical awareness and recognition of good practice in the area.

\subsubsection{Professional 1}

Barrett (2007) describes a portfolio as a collection of work and reflections which shows a student's growth over time 
or it is something that documents the learning of a student and helps with planning for the future (Kabilan and Khan, 2012). An electronic portfolio or ePortfolio is a digital version of the classic portfolio, owned by the student for collating experiences, achievements and learning (Gray, 2008). It acts as an online collection of a student's reflections over a defined period of time and helps to show that students growth over that time (Brown et al., 2007). Landis, Scott and Kahn (2015) found that reflection was not the primary motivation for users adopting ePortfolios but they very quickly became aware of its value. A significant finding for Professional 1 is the limited ability of students to reflect effectively.

In order to understand how to reflect effectively (since this is an aim of the multimedia resource) Professional 1 examined Gibb's (1988) Reflective Cycle. This starts with a description of what happened and then takes the thoughts and feelings of the practitioner into account; the point of note is that the reflective cycle involves a clear opportunity for the practitioner to do something different, to change an action from first instance, following an analysis and evaluation of what first happened. However, research on coaching behaviours carried out by Harvey, Cushion, Cope and Muir (2013) found that the participants, despite being experienced coaches, never reflected on their own practice. This is alarming given the documented importance of reflection in allowing practitioners the opportunity to become more aware of their practice.

An aim of the multimedia resource is to guide the user through the ePortfolio, but to do so in a way that actively engages them and facilitates them to learn by doing. To achieve this aim, he has examined literature in relation to developing interactive content in online education. It is important to keep the learner engaged to enhance their learning through the technology. Interactivity involves the prompting of the learner to respond in some way to the presented content. Interactive instructional design is important in ensuring learning satisfaction and success. The risk could be that interactivity increases the complexity at the expense of the pedagogical value (Sun and Hsu 2012). Typical ways of prompting interactivity in eLearning include asking questions, simulating scenarios and video and animation presentations: 'An interactive multimedia module can visually stimulate a student and transform learning into an active, engaging process' (Violante and Vezzetti, 2015, p. 2).

Furthermore, there is evidence to show that the most important type is the interaction between the student and the content of the course (Herman and Mustea, 2016).

ePortfolios are consistent with social constructivist theory. Buzzetto-More (2010, p.61) said that 'Electronic portfolios (e-portfolios) are a paradigm in constructivist e-learning' and Paulson and Paulson (1994) claimed that there was no form of eLearning more constructivist than an ePortfolio. Bright (2016) drew on the relationship between the features of the ePortfolio Mahara software and social constructivism. For example, the group features and the sharing ability within ePortfolios allows for the conversations, comments and feedback between students. This is also closely linked to the CEP's strategic goal to implement a blended learning approach, which would develop communities of practice so that coaches can meet regularly, share experiences, best practices and learn how to coach better. In terms of individual learning, most ePortfolios (Mahara being one) include a journal feature allowing the student to reflect on their own learning and construct their own meaning. It is this feature, the reflective feature, which he hopes will support the coach to enhance their knowledge and performance.

\subsubsection{Professional 2}

Identifying with constructivist learning theories, which 'views learners as active creators of knowledge' (Alessi and Trollip, 2001, p. 17), Professional 2 plans to create a video that would support the viewer in becoming an active creator of knowledge. Supporting the constructivist approach and the belief that the learner is an 'active creator of knowledge' Brame (2015) identifies cognitive load, non-cognitive elements that impact engagement, and features that promote active learning, as being necessary considerations when designing and publishing video as an effective educational tool.

Efforts to promote active learning through his video will be guided by Koumi's (2006) Pedagogic Video Design Principles, particularly those on signposting, constructive learning and consolidation. Further insights into effective design strategies for enhancing student engagement with video will come from Guo (2014) on length of video, Mayer's Personalisation Principle (2008) on using a 'conversational' style and Lawson (2006) on using guiding questions.

The presentation of a meaningful narrative is essential in the video production in terms of engaging and involving the learner in the process, as well as providing a means in which they can seek to explore and develop themselves and their coaching practice. Narrative is essential to meaning making and is a fundamental structure of human meaning making (Rossiter, 2003). Furthermore, the Personalisation Principle (Mayer 2008, p. 766) encourages the use of a conversational style over a more formal 
style when presenting words in multimedia lessons as this 'creates a sense of social partnership with the narrator in which learners try harder to make sense of what their conversational partner is saying.' In this regard, the input of 'real' coaches sharing their insights and experiences in the video will create a more conversational and personalised effect, and may inspire current and prospective coaches in the organisation. Using inspirational stories to connect with others is highlighted by neuroscientist Immordino-Yang (2011) who points to the effect that such stories can have on our neurological and biological system and how we feel the implications of those stories on the very same neural systems that literally keep us alive. In Gaelic games, as in most other pursuits, inspiration often comes from the stories of the lives, experiences and deeds of great players and coaches.

\section{Conclusion}

This article has highlighted the research work of two eLearning professionals who are currently seeking to transform the experience of the GAA CEP and ease the transition from the traditional face-to-face delivery to a blended learning approach. While it has not highlighted the effect of the transformation on the organisation (as it is research in progress), it has succeeded in highlighting the efforts, skills and knowledge that they are bringing to their workplace. Their collaboration with DCU is developing their workplace learning as it has contributed to their understanding of pedagogy, culture and the challenges therein. They have already become agents of change by developing these educational multimedia resources, but one of their biggest challenges yet will be involving leaders at all levels to engage enthusiastically about their chosen technologies in order to increase engagement in the CEP. Horgan and Daly (2015, p 355) rightly point out that 'through collaboration between academics and practitioners we can develop a better understanding of coach development, and implement learning centred coach development programmes that will improve the experiences for our coaches and athletes'. This work in progress is not only significant in terms of improving their workplace for present coaches, but it will undoubtedly have a ripple effect by transforming the future of players and communities around the country.

\section{References}

[1] Alessi, S.M., \& Trollip, S.R. (2001). Multimedia for Learning: Methods and Development. Boston, MA: Allyn and Bacon, Inc

[2] Barrett, H. C. (2007). Researching electronic portfolios and learner engagement: The REFLECT initiative. Journal of Adolescent and Adult Literacy, 50(6), 436-449

[3] Balish, S.M., McLaren, C., Rainham, D., \& Blanchard, C. (2014). Correlates of youth sport attrition: A review and future directions. Psychology of Sport and Exercise, 15(4), 429-439

[4] Brame, C.J. (2015). Effective educational videos. Centre for Teaching, Vanderbilt University. https://cft.vanderbilt.edu/ guides-sub- pages/effective-educational- videos/ (accessed 10th May 2016]

[5] Bright, S., (2016). ePortfolios, social constructivism and assessment: A match made in heaven. There and back: Charting flexible pathways in open, mobile and distance education. http://bit.ly/mahara_DEANZ16 (accessed 10th August 2016)

[6] Brown, M., Anderson, B., Simpson, M., \& Suddaby, G. (2007). Showcasing Mahara: A new open source ePortfolio. Proceedings ascilite Singapore, 82-84

[7] Buzzetto-More, N. (2010). Assessing the efficacy and effectiveness of an e-portfolio used for summative assessment. Interdisciplinary Journal of E-Learning and Learning Objects, 6(1), 61-85

[8] Crotty, Y., \& Kilboy, L. (2015). The Co-Creation of an Innovative Video using an Educational Entrepreneurial approach to inspire Humanitarianism. Paper presented at Humanitarian Innovation Conference at Keble College, Oxford University. http://www. oxhip.org/resources/hip2015papers/

[9] Crotty, Y. (2014). Promoting a Creative Educational Entrepreneurial Approach in Higher Education. International Journal for Transformative Research, 1(1), 75-100

[10] Daly, P. (2014), Iomáin: Tradition in Practice: How Ireland and Scotland's Celtic Rivalry Influenced the Development of the Modern-Day Game of Iomáin. goo.gl/YoYiuX (accessed on 24th September 2016)

[11] Horgan, P., \& Daly, P. (2015). The Role of the Coach Developer in Supporting and Guiding Coach Learning. A Commentary. International Sport Coaching Journal, 2, 354-356

[12] Gibbs, G. (1988). Learning by doing: A guide to teaching and learning methods. Further Education Unit. Oxford: Oxford Polytechnic

[13] Gray, L. (2008). Effective Practice with e-Portfolios. Supporting 21st century learning. JISC Innovation Group. http://www. ssphplus.info/files/effective_practice_e-portfolios.pdf (accessed 23rd August, 2016)

[14] Guo, P.J., Kim, J., \& Robin, R. (2014). How video production affects student engagement: An empirical study of MOOC videos. http://pgbovine.net/publications/edX-MOOC-videoproduction-and-engagement_LAS-2014.pdf (accessed 14th August 2016)

[15] Harvey, S., Cushion, C. J., Cope, E., \& Muir, B. (2013). A season long investigation into coaching behaviours as a function of practice state: The case of three collegiate coaches. Sports Coaching Review, 2(1), 13-32

[16] Herman, C., \& Mustea, A., (2016). The Development of Interactive Content. In The International Scientific Conference 
eLearning and Software for Education. Proceedings of the 12th International Scientific Conference 'eLearning and Software for Education', Bucharest, April 21-22, 2016

[17] Immordino-Yang, M. H. (2011). Embodied Brains, Social Minds. https://www.youtube.com/watch?v=RViuTHBIOq8 (accessed August, 21st 2016)

[18] Kabilan, M.K., \& Khan, M.A. (2012). Assessing pre-service english language teachers' learning using e-portfolios: Benefits, challenges and competencies gained. Computers and Education, 58(4), 1007-1020

[19] Koumi, J. (2006). Designing video and multimedia: For open and flexible learning. Oxon: Routledge

[20] Landis, C.M., Scott, S.B., \& Kahn, S. (2015). Examining the Role of Reflection in ePortfolios: A Case Study. International Journal of ePortfolio, 5(2), 107-121

[21] Lawson ,T.J, Bodle, J.H, Houlette, M.A., \& Haubner, R.R. (2006). Guiding questions enhance student learning from educational videos. Teaching of Psychology, 33, 31-33

[22] Mayer, R.E., (2008). Applying the science of learning: evidence-based principles for the design of multimedia instruction. American Psychologist, 63(8), 760
[23] McCullick, B. (2012). Preliminary Recommendations Report for GAA Coach Education Programme. http://learning.gaa.ie/sites/ default/files/McCullickReport.pdf (accessed 21st August 2016)

[24] Paulson, F.L., \& Paulson, P. (1994). Assessing Portfolios Using the Constructivist Paradigm. In Fogarty, R. (Ed.) (1996) Student Portfolios. Palatine: IRI Skylight Training \& Publishing

[25] Rosenberg, M.J. (2001). E-learning: strategies for delivering knowledge in the digital age. New York: McGraw-Hill

[26] Rossiter, M. (2003) Narrative and Stories in Adult Teaching and Learning. ERIC Digest, 241

[27] Schein, E.H. (2010). Organizational culture and leadership. San Francisco, CA: Jossey-Bass

[28] Sun J., \& Hsu, Y. (2012). An experimental study of learner perceptions of the interactivity of web-based instruction. Interacting with Computers, 24(1), 35-48

[29] Violante, M.G., \& Vezzetti, E. (2015). Virtual interactive elearning application: An evaluation of the student satisfaction. Computer Applications in Engineering Education, 23(1), 72-91 